\title{
MANGANESE FERRITE THIN FILMS PART I: PREPARATION AND STRUCTURE*
}

\author{
W. S. HULSCHER, K. G. V.D. BERG AND J. C. LODDER \\ Department of Electrical Engineering, Twente University of Technology, Enschede (The Netherlands)
}

(Received July 27, 1971)

SUMMARY

The preparation of manganese ferrite thin films by the reactive evaporation of oxidic materials is reported. The process is not critical and provides homogeneous mirror-like films with spinel structure. An annealing procedure below $750^{\circ} \mathrm{C}$ has a strong influence on the properties of the films. Special attention is paid to the partial oxygen pressure during the annealing process. For this purpose data are collected from the literature concerning the equilibrium conditions of the spinel structure for varying manganese-iron contents. The lattice constant of the spinel structure of the films is determined by electron diffraction.

\section{INTRODUCTION}

Many studies have been reported on the structure and magnetic properties of manganese ferrite. These concern the bulk material in either a single crystalline or polycrystalline form. A limited number of studies has been published on manganese ferrite films ${ }^{1-5}$. The shape of a thin film is however interesting on account of (a) the influence of the shape anisotropy on the magnetic properties (b) the possibilities for special methods of investigation (Faraday effect, transmission electron microscopy) (c) the present interest in the application of oxidic magnetic films as memory materials (d) the possible application of ferrite films in microwave techniques. Moreover a thin film made by vacuum deposition can provide a material composed of very small crystallites, in contrast to normal ceramic techniques. The crystallite size largely influences certain magnetic

\footnotetext{
* Part II: Properties, see Thin Solid Films, 9 (1972) 377-388.
} 
properties of the material. The fact that so few studies on manganese ferrite films are known is possibly connected with problems in their preparation. These problems are related to the complicated phase diagram ${ }^{6,7}$ of the material. Both iron and manganese may have more than one valency. At room temperature, in air, manganese ferrite, $\mathrm{Mn}_{\delta} \mathrm{Fe}_{3-\delta} \mathrm{O}_{4}(0<\delta<3)$ may exist only as an undercooled phase, for all values of $\delta$. These problems do not exist for a large number of other ferrite materials.

In work reported in the literature ${ }^{1-5}$ the chemical vapour deposition technique (CVD) has been used for the preparation of manganese ferrite films. In CVD a number of process parameters must be controlled within a very limited tolerance. This technique is undesirable in the making of films which are very homogeneous, smooth and thin. In investigations using the optical Faraday effect the films must be sufficiently thin. Manganese ferrite films are transparent in the visible up to a film thickness of typically $10000 \AA$, depending on the cation ratio. An important requirement for magneto-optical studies (Faraday and Kerr effect) is that the films must be very smooth. In this article the preparation of polycrystalline thin films of $\mathrm{Mn}_{\delta} \mathrm{Fe}_{3-\delta} \mathrm{O}_{4}$ made by reactive evaporation is reported. Special attention is paid to thermal annealing of the films with regard to the conditions for obtaining oxygen stoichiometry.

\section{PREPARATION}

For the production of the films we have chosen the reactive evaporation technique. Generally a sintered pill of $\mathrm{Mn}_{\delta} \mathrm{Fe}_{3-\delta} \mathrm{O}_{4}$ is used as the source material, but mixtures of powders of $\mathrm{Fe}_{2} \mathrm{O}_{3}$ and $\mathrm{MnO}$ can also be used. In principle there is no preference for either of these source materials. It was found that during the evaporation process in both cases the surface of the source material was converted into a (Mn, Fe)O phase. For practical reasons a sintered pill of $\mathrm{Mn}_{\delta} \mathrm{Fe}_{3-\delta} \mathrm{O}_{4}$ is preferable because due to its higher density more material (in our apparatus $5.5 \mathrm{~g}$ ) can be put in the limited volume of the source. This is important because the composition of the source material changes with time through a fractionation effect during the evaporation process. The composition of the source material remains more constant if its mass is larger. The source material is contained in a watercooled copper crucible in a belljar. Heating of the material is accomplished by electron bombardment from a tungsten ring cathode. The vacuum is $3 \times 10^{-7}$ torr before pure oxygen is admitted into the belljar. During evaporation a constant partial oxygen pressure of, at the most, $10^{-3}$ torr is maintained.

Substrates are suspended at a distance of $13-17 \mathrm{~cm}$ above the source. These substrates can be heated by a small furnace. The evaporation rate and the mass of the film are measured in situ with a quartz crystal monitor. After the evaporation 
process the mass of the film is also measured by weighing and the film thickness is measured by the Tolansky method.

Substrate materials are plates of Corning 7059 glass, ordinary microscope glass or quartz glass. For the electron microscope investigations special substrates in the form of a thin SiO film (ca. $250 \AA$ ) supported on a 200-mesh electron microscope grid, or substrates of mica coated with a thin film of amorphous carbon (ca. $250 \AA$ ) are suspended alongside the glass substrates. Ferrite films deposited on the grids coated with $\mathrm{SiO}$ can be used directly in transmission electron microscopy. The ferrite films supported on the carbon coated mica substrates must be separated from the mica for the same purpose. The separating can be done by carefully immersing the whole in distilled water. The small pieces of ferrite film and carbon, float on the water and can be picked up on an electron microscope grid. A suitable thickness of the manganese ferrite films for transmission electron microscopy (Philips EM 200) appears to be about $750 \AA$. The evaporation rates which are realized vary from 0 to $3 \AA / \mathrm{sec}$ depending on the heating power.

The detailed mechanism of the reactive evaporation process in making manganese ferrite films is not yet well known. In special evaporation experiments the externally admitted oxygen flow is kept constant so that the pressure in the belljar is controlled by the oxygen which dissociates from the source material. By following this pressure in the belljar during heating of the source it has been calculated that the higher oxides in the source reduce to a $(\mathrm{Mn}, \mathrm{Fe}) \mathrm{O}$ phase during the early stages of the heating process. This corresponds with the dissociation characteristics for manganese oxides and iron oxides at the prevailing temperatures and oxygen pressures ${ }^{8}$. In these first stages of heating no deposition rate at the substrates can be detected. By heating further up to a reasonable deposition rate (at about $1500^{\circ} \mathrm{C}$ ) it is questionable what happens. From the literature there are indications suggesting that the $(\mathrm{Mn}, \mathrm{Fe}) \mathrm{O}$ phase as a vapour dissociates further to metal vapour and oxygen ${ }^{9}$. In that case, at the substrate the metal vapour recombines with oxygen to form the resulting spinel structure. This latter process does not satisfy thermodynamical equilibrium conditions that are known for bulk material, because at the prevailing substrate temperatures $\left(100^{\circ}-400^{\circ} \mathrm{C}\right)$ in a partial oxygen pressure of $10^{-4}$ to $10^{-3}$ torr the spinel structure is not the equilibrium phase for this material.

It appears that a condition for obtaining the spinel structure is that per unit of time more oxygen molecules than metal containing molecules impinge on the substrate. (At an oxygen pressure of $10^{-3}$ torr and a deposition rate of $1 \AA / \mathrm{sec}$ this collision rate is about 350 ). This corresponds to the experiments on reactive evaporation of $\mathrm{SiO}$ and $\mathrm{SiO}_{2}$ by $\mathrm{Ritter}^{10}$.

In our experiments the process parameters (deposition rate, partial oxygen pressure, substrate temperature) appear not to be critical in obtaining homogeneous mirror-like manganese ferrite films with spinel structure. 


\section{THERMODYNAMIC EQUILIBRIUM CONDITIONS AND PHASE TRANSITIONS}

A thermal treatment of the as-evaporated films after the evaporation process is necessary to improve the crystallographic structure. The magnetic and electric properties are influenced by this annealing process. In the annealing process the thermodynamical equilibrium conditions must be taken into account. This is necessary for preventing phase separations and for controlling the oxygen fraction of the material. The character of the annealing process will also influence the cation distribution on the tetrahedral and octahedral positions of the spinel structure, but we have not followed this variation.

In this section some aspects of the phase diagram of the material are considered, in so far as it depends on the partial oxygen pressure of the surrounding gas. Following common usage we denote the general formula of manganese ferrite as $\mathrm{Mn}_{\delta} \mathrm{Fe}_{3-\delta} \mathrm{O}_{4+\gamma}$, which is to be considered as a chemical formula and not as a crystallographic formula. This implies that positive values of $\gamma$ mean in reality structures with metal ion vacancies, because it is not possible to place extra oxygen inside the densely packed oxygen ions of the spinel structure.

$\mathrm{Mn}_{\delta} \mathrm{Fe}_{3-\delta} \mathrm{O}_{4+\gamma}$ has the spinel structure within certain limits of temperature and partial oxygen pressure of the surrounding gas. This is the case for each $0 \leqq \delta \leqq 3$. The value of $\gamma$ is however restricted within narrow tolerances ${ }^{6}$. A too large negative value of $\gamma$ leads to a phase transition to a mangano-wustit phase, (Mn, $\mathrm{Fe}) \mathrm{O}$. A too large positive value of $\gamma$ leads to a transition to $\mathrm{Fe}_{2} \mathrm{O}_{3}$, $\mathrm{Mn}_{2} \mathrm{O}_{3}$ or both. The value of $\gamma$ is determined by the temperature and oxygen pressure of the surrounding gas.

Various authors ${ }^{6,7,11-13}$ give experimental results concerning the equilibrium conditions (oxygen pressure and temperature) at which the spinel phase coexists with an adjacent $(\mathrm{Mn}, \mathrm{Fe}) \mathrm{O}$ phase. The results are summarized in Fig. 1 with $\delta$ as parameter. The equilibrium conditions for oxygen stoichiometry $(\gamma=0)$ of the composition with $\delta=1$ can be calculated from the formula of Roshchupkin ${ }^{11}$, which was interpolated from experimental results:

$$
\log P_{\mathrm{O}_{2}}(\mathrm{~atm})=-165.01+44.289 n-1135.219 .10^{3} \cdot T^{-1}+277.462 n \cdot 10^{3} \cdot T^{-1}
$$

with the restriction $3.99 \leqq n \leqq 4.02$ while $n=\gamma+4$. This result is also represented in Fig. 1. The equilibrium conditions for an oxygen content close to stoichiometry $(\gamma=-0.013)$ of the composition with $\delta=1.023$ are given by Bulgakova et al. ${ }^{12}$. This is also represented in Fig. 1. Linear extrapolation of the dependence of Fig. 1 to the temperature $750^{\circ} \mathrm{C}$ gives the data of Fig. 2. In the latter figure the oxygen pressure at which phase transition occurs to either the reduced or the oxidized phase is given as a function of $\delta$. This gives us the borders of the spinel area at $750^{\circ} \mathrm{C}$ as a function of the metal composition. Also in Fig. 2 are given the points for $\delta \approx 1$ of refs. 11 and 12 at which oxygen stoichiometry 


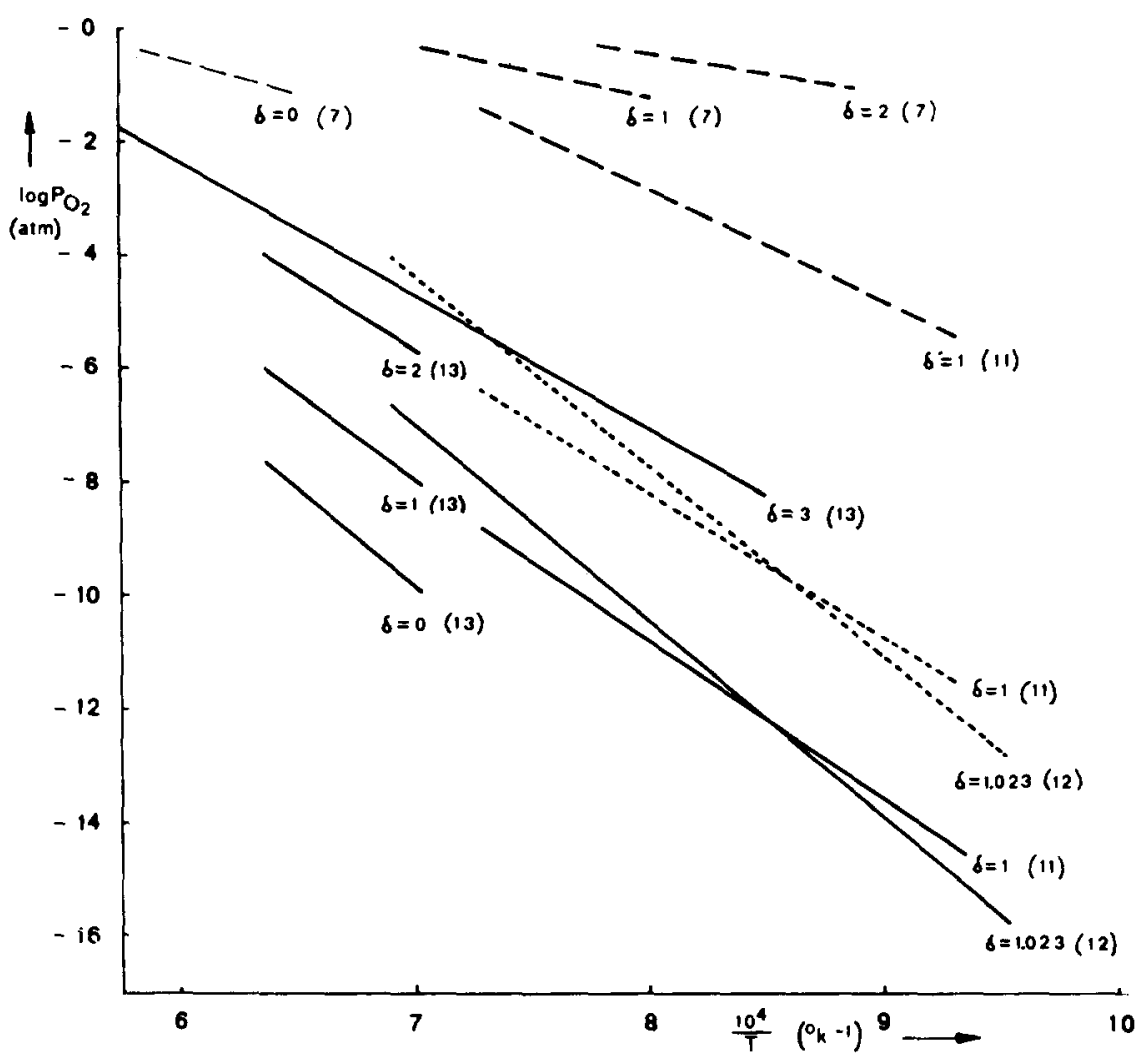

Fig. 1. Influence of the partial oxygen atmosphere on $\mathrm{Mn}_{8} \mathrm{Fe}_{3-\delta} \mathrm{O}_{4+\gamma}$ as a function of temperature with $\delta$ as a parameter. References are indicated in the figure. Dashed lines : equilibrium conditions for coexistence of spinel with an oxidized phase. Full lines: equilibrium conditions for coexistence of spinel with a reduced phase. Dotted lines: equilibrium conditions for stoichiometric spinel.

(or near oxygen stoichiometry) exists. These data at $750^{\circ} \mathrm{C}$ are especially important for our investigations, because a temperature of about $750^{\circ} \mathrm{C}$ appears to be the maximum annealing temperature for ensuring excellent surface conditions of the films.

It should be noted that the data from different authors do not agree completely. This is particularly clear in Figs. 1 and 2 at the composition which is most frequently investigated, $\delta \approx 1$. It is however difficult to establish the origin of these differences. For example in ref. 11 the deviation of the results from those of ref. 12 is noticed but not explained. It may be of importance that ref. 11 is based on measurements of electromotive forces and ref. 12 on thermogravimetric measurements. Likewise a striking difference exists over the phase transition to the oxidized phase, as is obvious from Fig. 2, refs. 11 and 7. This may be connected with the very special precautions, which are described in ref. 7 to avoid the metastable intermediate phase $\left(\mathrm{Mn}_{3} \mathrm{O}_{4} \cdot \mathrm{Fe}_{2} \mathrm{O}_{3}\right)$. Finally it should be mentioned 


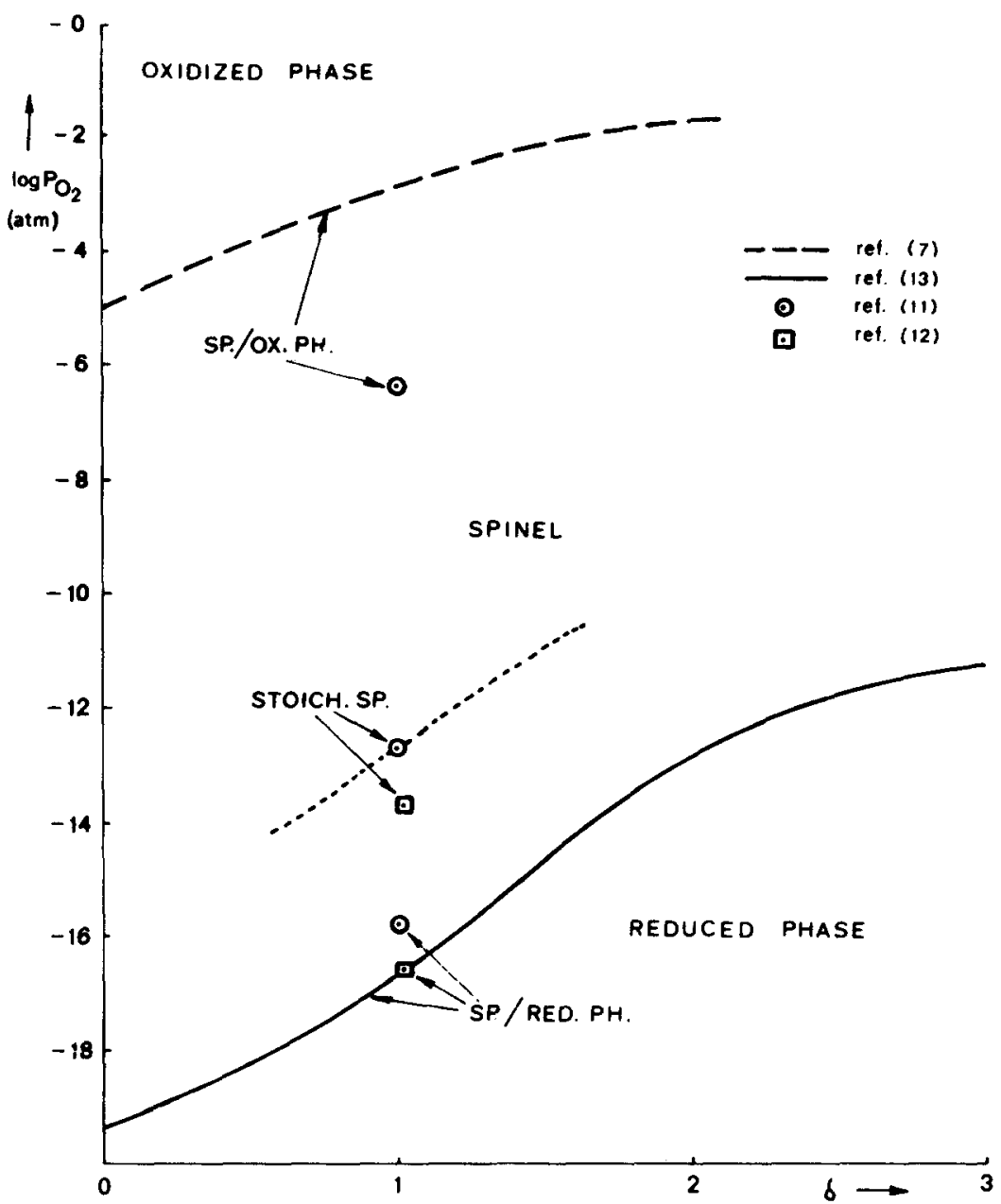

Fig. 2. Conditions of the partial oxygen atmosphere for equilibrium with $\mathrm{Mn}_{3} \mathrm{Fe}_{3-\delta} \mathrm{O}_{4+y}$ as a function of $\delta$ at $750^{\circ} \mathrm{C}$. The data are obtained from extrapolations of Fig. 1. The dotted line is an estimated condition for stoichiometric spinel $(\gamma=0)$.

that the estimates of Economos ${ }^{14}$ concerning the equilibrium conditions of $\mathrm{Fe}_{3} \mathrm{O}_{4}$ and $\mathrm{MnFe}_{2} \mathrm{O}_{4}$ are not confirmed by the data of the more recent studies. Economos' estimates, which were often used by other investigators, lie at too low oxygen pressures.

\section{ANNEALING}

The films are annealed in a furnace with an adjustable linear heating and cooling rate. The partial oxygen pressure in the furnace can be adjusted by conducting a controlled mixture of gases through the furnace. The admitted gases

Thin Solid Films, 9 (1972) 363-375 
consist of $\mathrm{CO}_{2}$ and a mixture of $\mathrm{H}_{2}$ and $\mathrm{N}_{2}\left(1 \%\right.$ and $99 \%$ respectively). The $\mathrm{N}_{2}$ only serves as a carrier gas for the required low amounts of $\mathbf{H}_{2}$. Before mixing with $\mathrm{H}_{2}$ the $\mathrm{CO}_{2}$-gas is purified from oxygen by leading it through copper granules at $520^{\circ} \mathrm{C}$. In the furnace an equilibrium is established following the reactions :

$$
\begin{aligned}
& 2 \mathrm{CO}_{2} \rightleftarrows 2 \mathrm{CO}+\mathrm{O}_{2} \\
& \mathrm{CO}_{2}+\mathrm{H}_{2} \rightleftarrows \mathrm{CO}+\mathrm{H}_{2} \mathrm{O} .
\end{aligned}
$$

The equilibrium constants of the reactions (1) and (2) are $K_{1}$ and $K_{2}$ respectively. As $K_{1} \gg K_{2}$ it can be deduced that, for not too small amounts of $\mathrm{H}_{2}$ :

$$
\log P_{\mathrm{O}_{2}}=\log K_{1}+2 \log \frac{P_{\mathrm{CO}_{2}(\mathrm{i})}}{P_{\mathrm{H}_{2}(\mathrm{i})}}
$$

in which the indices (i) indicate the initial partial pressure of the particular gas. The value of $K_{1}$ as a function of temperature is given by Darken $e t$ al. ${ }^{15}$ and by Smiltens ${ }^{16}$. By adjusting separately the flow rates of the $\mathrm{CO}_{2}$ and the $\mathrm{H}_{2}-\mathrm{N}_{2}$ mixture the required low partial oxygen pressures can be obtained in the furnace.

The slope of the temperature dependence of $K_{1}$ does not differ too much from that of the temperature dependence of the equilibrium oxygen pressure of $\mathrm{Mn}_{\delta} \mathrm{Fe}_{3-\delta} \mathrm{O}_{4}$, at least for not too high values of $\delta$. Because of this no large deviations of the equilibrium conditions arise during the heating and cooling period. These deviations may be corrected as required by adjusting the composition of the gas mixture with the temperature.

Quenching of the film after annealing is to be avoided because of the very large surface-to-volume ratio of the samples and the relatively large heat capacity of the substrate. The quenching process should be very fast to prevent phase transition of a considerable fraction of the film. For these reasons we prefer a gradual cooling process ( 2 to 5 degrees per $\mathrm{min}$ ) to room temperature in a controlled equilibrium atmosphere. At room temperature no changes in structure occur, so that the spinel structure remains, even in air, as an undercooled phase.

A number of evaporated films has been annealed in various conditions of temperature, oxygen pressure, time and cooling rate. The influence of these treatments on some special properties of the films is described in the next section and in Part II. In general it may be stated that an annealing treatment of several hours below $750^{\circ} \mathrm{C}$ greatly increases the crystallite size. In particular the less oxygen is contained in the annealing atmosphere, the more the crystallite growth is promoted (see Table I). The specimens can resist an oxidizing atmosphere at $750^{\circ} \mathrm{C}$ for several hours and still retain the spinel structure. But a reducing atmosphere can cause a rapid phase transition. These transitions to a reduced phase take place at conditions corresponding to the lower boundary of Fig. 2. Phase separations, if present, have been detected by transmission electron 


\section{TABLE I}

TYPICAL CRYSTALLITE SIZE OF EVAPORATED FILMS OF $\mathrm{Mn}_{\downarrow} \mathrm{Fe}_{3-\gamma} \mathrm{O}_{4+\gamma}$ CORRELATED WITH CONDITIONS OF ANNEALING (FOR $3 \mathrm{H}$ AT ANNEALING TEMPERATURE $T_{\text {an }}$ AND PARTIAL OXYGEN PRESSURE $P_{\mathrm{O}_{2}}$ )

\begin{tabular}{|c|c|c|c|c|}
\hline Sample & $\begin{array}{c}T_{\text {an }} \\
\left({ }^{\circ} \mathrm{C}\right)\end{array}$ & $\begin{array}{c}\log P_{\mathrm{O}_{2}} \\
\left(P_{\mathrm{O}_{2}} \text { in atm }\right)\end{array}$ & $\begin{array}{c}\text { Crystallite } \\
\text { size }(A)\end{array}$ & Notes \\
\hline \multirow{6}{*}{$\begin{array}{l}\text { (1) } \delta=0.85 \\
\text { film thickness } 480 \AA\end{array}$} & \multicolumn{2}{|c|}{ Unannealed } & $<100$ & \multirow{5}{*}{ (a) } \\
\hline & 750 & -6.4 & 200 & \\
\hline & 750 & -10.5 & 600 & \\
\hline & 750 & -13.1 & 1000 & \\
\hline & 750 & -13.8 & 1400 & \\
\hline & \multicolumn{2}{|c|}{ Unannealed } & $<100$ & \multirow{3}{*}{$\begin{array}{l}\text { (a) } \\
\text { (b) }\end{array}$} \\
\hline \multirow{2}{*}{$\begin{array}{l}\text { (2) } \delta=0.77 \\
\text { film thickness } 750 \AA\end{array}$} & 750 & -13.0 & 1400 & \\
\hline & 860 & -10.3 & 3000 & \\
\hline \multirow{2}{*}{$\begin{array}{l}\text { (3) } \delta=0.87 \\
\text { film thickness } 10000 \AA\end{array}$} & \multicolumn{2}{|c|}{ Unannealed } & $<100$ & \\
\hline & 950 & -5 & 10000 & (b) \\
\hline
\end{tabular}

Note (a) annealing conditions near equilibrium for $\gamma=0$

(b) rough surface

microscopy and electron diffraction. In some cases phase separations can also be observed by transmission microscopy with polarized light.

In general the surface condition of the annealed film is good, except for films which have been annealed above $c a .750^{\circ} \mathrm{C}$. The cause of the deterioration above $750^{\circ} \mathrm{C}$ is the increased influence of the difference between the thermal expansion coefficient of the manganese ferrite film (about $12 \times 10^{-6}$ per degree ${ }^{17}$ ) and the substrate (about $9 \times 10^{-6}$ per degree for glass and $5 \times 10^{-6}$ per degree for the Corning glass). Particularly unfavourable in this respect are quartz substrates, which have a thermal expansion coefficient of $0.5 \times 10^{-6}$ per degree. However the surface condition of the film depends also on the partial oxygen pressure during annealing. This is explained by the fact that an oxidizing atmosphere enlarges the oxygen content of manganese ferrites, which leads to contraction of the material ${ }^{6}$, whereas a reducing atmosphere has the opposite effect. This effect can greatly dominate the "normal" thermal expansion, as shown by Brabers ${ }^{18}$ for bulk $\mathrm{Mn}_{2} \mathrm{FeO}_{4+\gamma}$.

\section{COMPOSITION AND STRUCTURE}

All as-evaporated films are mirror-like and homogeneous to visual observation. Scanning by electron probe microanalysis along several centimetres of the surface of the films did not show any variation of the metal ratio. There are however small variations of the metal ratio along the thickness of the films. 
In this direction $\delta$ may vary by an amount of $c a .0 .01$ over $2000 \AA$. The latter conclusion can be drawn from wet polarographical analysis of film samples made in successive stages of the evaporation process.

The difference between $\delta$ in the compositions $\mathrm{Mn}_{\delta} \mathrm{Fe}_{3-\delta} \mathrm{O}_{4}$ of the film and the source material is represented by an iron loss of about $50 \%$ for all values of $\delta$ of the source material. Herein is defined:

$$
\% \mathrm{Fe} \text { loss }=\frac{100}{(\mathrm{Fe} / \text { metal })_{\text {source }}}\left\{(\mathrm{Fe} / \text { metal })_{\text {source }}-(\mathrm{Fe} / \text { metal })_{\text {film }}\right\} .
$$

The nominal iron loss varies however with the stage of the evaporation of the source at which the film is made and possibly with the partial oxygen pressure during evaporation. The former dependence is due to the change of the composition of the source material during heating, because of the fractionation effect.

All investigated as-evaporated films show the spinel structure only. Lines of structures other than spinel are not seen in the diffraction patterns. A considerable line broadening of the electron diffraction patterns (Fig. 3c) is due to the very small crystallite size of the films. The crystallites are smaller than $100 \AA$. Their size is somewhat dependent on the preparation conditions. In X-ray diffraction these micro-polycrystalline films seem amorphous. Rather good electron diffraction patterns can be obtained however.

Figure 3(d) shows the electron diffraction pattern of an annealed film. Because of crystallite growth line broadening has disappeared. Careful calibration of the electron microscope with the help of a thin film of $\mathrm{TICl}$ and recording of the diffraction patterns with the help of a micro-densitometer allow the measurement of lattice constants with an accuracy of $0.2 \%$. This gives a good conformity of the results with the literature data on the spinel structure of manganese ferrites, which have all been obtained by X-ray diffraction on bulk material. Table II shows that the electron diffraction lines of the film sample of Fig. 3(d) can all be identified in comparison with the ASTM standard for the spinel structure of $\mathrm{MnFe}_{2} \mathrm{O}_{4}$. The same is true for all films of Table III, which have been annealed in different partial oxygen pressures. No other phases can be detected in these films. The lattice constants of the annealed films of $\mathrm{Mn}_{0.85} \mathrm{Fe}_{2.15} \mathrm{O}_{4+\gamma}$ agree within $0.2 \%$ with the interpolations of the most recent literature data of bulk material of the same composition (Table III).

Figure 3(b) gives a picture of the crystallite structure of an annealed film. By darkfield electron microscopy it has been observed that there is no preferential orientation of the crystallites. At the same time it appeared that the films are composed of a single sheet of crystallites. Table I gives the mean crystallite size of some typical films, as measured along a direction in the film plane. The crystallite size is influenced by the nature of the annealing process. Larger crystallites are obtained by higher annealing temperatures, less oxidizing 

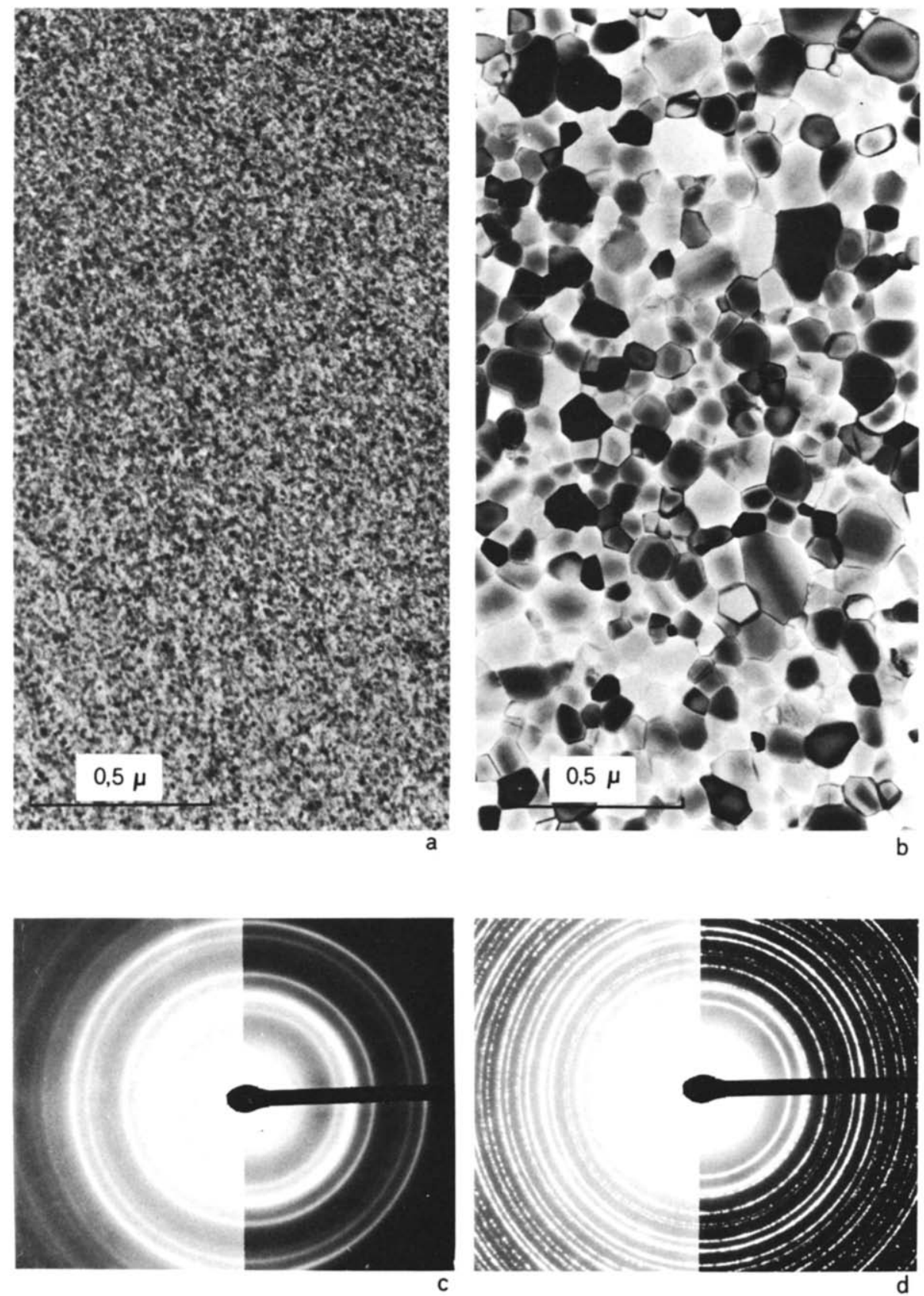

Fig. 3. Electron micrographs of an evaporated manganese ferrite film, $\mathrm{Mn}_{0.85} \mathrm{Fe}_{2.15} \mathrm{O}_{4+\gamma}$, about $500 \AA$ thick. (a) the as-evaporated film, (b) the same film after annealing for $3.5 \mathrm{~h}$ at $750^{\circ} \mathrm{C}$ in a partial oxygen-pressure of $10^{-10.5} \mathrm{~atm}$., (c) electron diffraction pattern of the as-evaporated film, (d) electrondiffraction pattern of the annealed film.

Thin Solid Films, 9 (1972) 363-375 
TABLE II

DIFFRACTION LINES OF MANGANESE FERRITE SPINEL

\begin{tabular}{cccc}
\hline $\begin{array}{l}\text { Present study by electron diffraction } \\
\text { on a thin film of } \mathrm{Mn}_{0.85} \mathrm{Fe}_{2.15} \mathrm{O}_{4+\gamma}\end{array}$ & $\begin{array}{l}\text { ASTM } 10-319, X \text {-ray diffraction on } \\
\text { bulk } \mathrm{MnFe}_{2} \mathrm{O}_{4}\end{array}$ \\
\hline$d(A)$ & $a(A)$ & $h, k, l$ & $d(A)$ \\
\hline 4.912 & 8.508 & 111 & 4.906 \\
4.259 & 8.518 & 200 & $-{ }^{*}$ \\
3.008 & 8.510 & 220 & 3.005 \\
2.562 & 8.498 & 311 & 2.563 \\
2.456 & 8.508 & 222 & 2.450 \\
2.126 & 8.506 & 400 & 2.124 \\
1.952 & 8.510 & 331 & $-{ }^{*}$ \\
1.900 & 8.496 & 420 & $-{ }^{*}$ \\
1.735 & 8.500 & 422 & 1.7342 \\
1.636 & 8.501 & 511,333 & 1.6355 \\
1.503 & 8.503 & 440 & 1.5031 \\
1.438 & 8.505 & 531 & 1.4376 \\
1.417 & 8.504 & 600,422 & $-{ }^{*}$ \\
1.344 & 8.503 & 620 & 1.3441 \\
1.296 & 8.498 & 533 & 1.2962 \\
1.280 & 8.492 & 622 & 1.2810 \\
1.226 & 8.495 & 444 & 1.2276 \\
1.191 & 8.506 & 711,551 & 1.1898 \\
1.178 & 8.492 & 640 & $-{ }^{*}$ \\
1.136 & 8.498 & 642 & 1.1355 \\
1.1062 & 8.497 & 731,553 & 1.1063 \\
1.0625 & 8.500 & 800 & 1.0623 \\
\hline
\end{tabular}

* These reflections are forbidden in space group $\mathrm{Fd} 3 \mathrm{~m}$. Our measurements correspond with the space groups $F \ldots$.

annealing atmospheres and longer annealing times. (The process of crystallite growth is not completed after $3 \mathrm{~h}$ of annealing at $750^{\circ} \mathrm{C}$.) In general the mean crystallite size is small compared with normal bulk materials; this has a bearing on the process of magnetisation reversal (see Part II).

\section{DISCUSSION}

In work on manganese ferrite films so far reported in the literature, the method of preparation has been the CVD technique ${ }^{1-5}$. In comparison, our method of preparation of manganese ferrite films does not suffer from some of the restrictions which are encountered in the CVD technique. In reactive evaporation the making of very thin films can be controlled by the use of a low deposition rate. There appears to be no composition gradient along the surface of the substrates and the composition gradient along the film thickness is very small. High substrate 
TABLE III

LATTICE CONSTANT OF THE SPINEL PHASE OF $\mathrm{Mn}_{0.85} \mathrm{Fe}_{2.15} \mathrm{O}_{4+\gamma}$

\begin{tabular}{llll}
\hline Annealing and cooling conditions & Lattice constant $(A)$ & Reference \\
\hline & \multicolumn{1}{l}{$\log \mathrm{P}_{\mathrm{O}_{2}}$} & & \\
\cline { 2 - 2 } & -6.4 & $8.483 \pm 0.016$ & $\begin{array}{l}\text { Present study by electron } \\
\text { diffraction on evaporated films }\end{array}$ \\
$\begin{array}{l}\text { Slowly cooled in } \\
\mathrm{CO}_{2}-\mathrm{H}_{2} \text { mixture after }\end{array}$ & -10.5 & $8.500 \pm 0.016$ & \\
$\begin{array}{l}3 \mathrm{~h} \text { annealing at } 750^{\circ} \mathrm{C} \\
\text { in partial oxygen } \\
\text { pressure } P_{\mathrm{O}_{2}}\end{array}$ & -13.8 & $8.487 \pm 0.016$ & \\
$\begin{array}{l}\text { Quenched after } 4 \mathrm{~h} \text { annealing at } \\
400^{\circ} \mathrm{C} \text { close to equilibrium } \\
\text { oxygen pressure }\end{array}$ & 8.500 & $\begin{array}{l}\text { Interpolated from ref. } 29 \text { (bulk } \\
\text { material) }\end{array}$ \\
$\begin{array}{l}\text { Quenched after } 8 \text { days annealing } \\
\text { at } 1000^{\circ} \mathrm{C} \text { at stoichiometric } \\
\text { conditions }\end{array}$ & 8.499 & $\begin{array}{l}\text { Interpolated from ref. } 30 \text { (bulk } \\
\text { material) }\end{array}$ \\
$\begin{array}{l}\text { Quenched after annealing at } \\
1400^{\circ}-1447^{\circ} \mathrm{C}\end{array}$ & 8.467 to 8.497 & $\begin{array}{l}\text { See for references Fig. } 3 \text { of ref. } 19 \\
\text { (bulk material) }\end{array}$ \\
\hline
\end{tabular}

temperatures are not required, so there is no diffusion of atoms from the substrate into the film. Finally no critical adjustment of the process parameters is necessary to obtain smooth (mirror-like) films.

The method of reactive evaporation of an oxidic source may also be compared with other vacuum techniques, which have been reported for the preparation of thin films of other ferrite compositions than manganese ferrite ${ }^{20-28}$. For instance if no reactive oxygen atmosphere is used ${ }^{20-22}$, an oxidation step is necessary afterwards to obtain the spinel structure. This has to be done at high temperatures (at least $1000^{\circ} \mathrm{C}$ ), which results in a bad surface condition of the film and large stresses, and also the choice of the substrate is seriously limited. Furthermore instead of evaporation a sputtering technique can be used ${ }^{23-28}$. The difference is rather of a technical nature than one of principle, even for the fractionation effect. It is not correct to say that by sputtering a film is always obtained with the same composition as the source material. This has been shown very clearly by Sawatzky and $\mathrm{Kay}^{27}$ for the case of gadolinium iron garnet.

Finally the oxidic source is especially favourable in the case of manganese ferrite. The reason is that the metals themselves, i.e. manganese and iron, have very different vapour pressure characteristics $\left(\right.$ at $1000^{\circ} \mathrm{C}$ the equilibrium vapour pressure of manganese is about $10^{5}$ times that of iron). So the use of a metallic source leads to a very large fractionation effect, which is difficult to control. In comparison, the use of the oxidic source material causes a fairly limited 
fractionation effect, which can be compensated by adjusting the composition of the source material. (The ratio of the vapour pressures of $\mathrm{MnO}$ to $\mathrm{FeO}$ is 5.3 at $1500^{\circ} \mathrm{C}^{9}$ ). The manganese ferrite films which we have prepared provide good opportunities for the study of various phenomena in ferrimagnetic films. Some physical properties of the films will be described in Part II.

\section{REFERENCES}

1 G. I. Frolov, N. M. Salanskit, Ya. A. Zaionchkovskit, V. V. Lyukshin, B. P. Trubitsyn and Yu. V. UtKin, Bull. Acad. Sci. USSR, Phys. Ser., 31 (1967) 435.

2 G. R. Pulliam, J. Appl. Phys., 38 (1967) 1120; G. R. Pulliam, R. G. Warken, R. E. Holmes and J. L. ArCher, J. Appl. Phys., 38 (1967) 2192.

3 J. J. Hanak and D. Johnson, J. Appl. Phys., 39 (1968) 1161.

4 V. V. LYUKSHIN, Inorg. Mater, 5 (1969) 1478.

5 H. SCHRöDER AND P. GöRNERT, Krist. U. Techn., 4 (1969) 365.

6 D. G. WICKHAM, J. Inorg. Nucl. Chem., 31 (1969) 313.

7 N. G. Schmahl and D. Hennings, Z. Phys. Chem. N.F., 64 (1969) 313.

8 S. Dushman AND J. M. LAFERTY, Scientific Foundations of Vacuum Technique, Wiley, New York, 1962.

9 L. Brewer and D. F. Mastick, J. Chem. Phys., 19 (1951) 834.

10 E. RitTER, J. Vac. Sci. Technol., 3 (1966) 225.

11 V. 1. RoshchupKIN, Inorg. Mater., 5 (1969) 1541.

12 T. I. Bulgakova, O. S. Zaitsev and A. G. Rozanov, Russ. J. Phys. Chem., 40 (1966) 590.

13 K. Schwerdtfeger and A. MUan, Trans. Metal. Soc. AIME, 239 (1967) 1114.

14 G. Economos, J. Am. Ceram. Soc., 38 (1955) 241.

15 L. S. Darken and R. W. Gurry, J. Am. Chem. Soc., 67 (1945) 1398.

16 J. Smiltens, J. Chem. Phys., 20 (1952) 990.

17 YA. M. BeKKer AND G. M. Zotova, Inorg. Mater., 4 (1968) 1155.

18 V. A. M. Brabers, Thesis, Technische Hogeschool Eindhoven, The Netherlands, 1970.

19 A. Muan and S. SömiYa, Am. J. Sci., 260 (1962) 230.

20 M. H. Francombe, J. E. Rudisill and R. L. Coren, J. Appl. Phys., 34 (1963) 1215.

21 E. Banks, N. H. Riederman, H. W. Schleuning and L. M. Silber, J. Appl. Phys., 32 (1961) 44S.

22 G. Suran and L. Néel, C. R. Acad. Sci. Paris, 266 (1968) 998.

23 O. P. Pavlyuchenko, G. V. Spivak and V. V. Shakmanov, Bull. Acad. Sci. USSR, Phys. Ser., 29 (1965) 628.

24 L. V. Kirenskit, P. S. Galepov and 1, A. Turpanov, Sov, Phys. Cryst., 11 (1966) 314.

25 M. Paulus and R. Morineau, Le Vide, 130 (1967) 203.

26 W. D. Westwood, H. K. Eastwood, R. G. Poulsen and A. G. Sadler, J. Am. Ceram. Soc., 50 (1967) 119.

27 E. Sawatzky and E. Kay, IBM J. Res. Develop., 13 (1969) 696.

28 D. S. Lo, G. F. Sauter and W. J. Simon, J. Appl. Phys., 40 (1969) 5402.

29 V. F. Komarov, N. N. Oleinikov, Yu. G. Saksonov and Yu. D. Tret'yakov, Inorg. Mater., 1 (1965) 365.

30 Yu. D. Tret'yakov, Yu. G. Saksonov and I. V. Gordeev, Inorg. Mater., I (1965) 382. 